\title{
Análise das restrições de acesso a dados de espécies ameaçadas, previstas em políticas de coleções biológicas científicas brasileiras, à luz do direito ambiental e da ciência da informação
}

\author{
Marcos Gonzalez \\ Mestre em botânica pelo Instituto de Pesquisas Jardim Botânico do \\ Rio de Janeiro (JBRJ). Tecnologista do Instituto de Pesquisas Jardim \\ Botânico do Rio de Janeiro, Rio de Janeiro, RJ, Brasil. \\ E-mail:gonzalez@jbrj.gov.br
}

\section{Resumo}

Este artigo analisa se as políticas de acesso a dados armazenados em coleções biológicas, produzidas no âmbito do Programa de Pesquisa em Biodiversidade (PPBio) do Ministério de Ciência e Tecnologia (MCT), estão em conformidade com a legislação brasileira pertinente. Para tal avaliou-se se as restrições de acesso a dados de espécies ameaçadas de extinção, presentes em políticas de três instituições vinculadas ao MCT, estão previstas em lei ou são sustentadas pela ciência da informação. A conclusão é que não há, no direito brasileiro, nenhum diploma que sustente ou incentive restrições de acesso a dados de espécie biológica pelo fato de ela constar em alguma lista de espécies ameaçadas, e as políticas estudadas não estão, portanto, aderentes à legislação nem à mentalidade dominante na comunidade científica. Sugere-se que tais políticas sejam revistas com base em uma discussão ampla sobre o assunto, que é complexo e interessa a toda a sociedade.

\section{Palavras-chave}

Coleções biológicas. Espécies ameaçadas. Informação ambiental. Direito à informação.

\section{Analysis of restrictions on access to data of threatened species, found in policies for scientific biological collections in Brazil, in the light of the environmental laws and the information science}

\author{
Abstract \\ The objective of this article is to examine whether the \\ policies for access to data stored in biological collections \\ and produced by the Research Program in Biodiversity \\ (PPBio), Ministry of Science and Technology (MCT), are
}

in accordance to the relevant Brazilian legislation. It was evaluated whether the restrictions on access to data of threatened species, present in the policies of the three research institutes of MCT studied, are provided by law or sustained by the Information Science. The conclusion is that, according the Brazilian law, there is no support which provides for or encourages restrictions to accessing data of biological species because it is included in the list of threatenced species. Brazilian policies are not in accordance to the legislation or prevailing mentality in the scientific community. The suggestion is that, based on a broad discussion about the subject, these policies should be reviewed. This is a complex subject which concerns the whole society.

Keywords

Biological collections. Threatened species. Environmental law. Rights to Information.

\section{INTRODUÇÃO}

Espécimes biológicos vêm sendo continuamente colecionados há quase três séculos em diversas instituições de ensino e pesquisa, museus de história natural e herbários ao redor do mundo. Calculase que sejam em torno de 6.500 instituições e que reúnam entre 2,5 e 3 bilhões de exemplares (CANHOS, 2003; GRAHAM, FERRIER et al., 2004; GAIKWAD e CHAVAN, 2006). Trata-se de um patrimônio de valor incalculável sob muitos pontos de vista. Para as ciências biológicas, além de contarem a história da própria ciência, fornecem o melhor retrato possível da evolução de uma biota ao longo de alguns ou milhões de anos (BOWKER, 2000). Para os governos e economias, oferecem subsídios valiosos ao planejamento, estabelecimento, acompanhamento e avaliação de políticas públicas, de programas e projetos 
desenvolvimentistas, de alterações ambientais, de políticas conservacionistas e de manejo de recursos naturais e, em especial, à identificação de componentes da diversidade biológica que levem à descoberta de novos recursos e possibilidades para a saúde pública, agropecuária, indústria e outros setores econômicos (NOVAES, RIBAS et al., 2000; MAGALHÃES, SANTOS et al., 2001).

A Instrução Normativa (IN) n. ${ }^{\circ} 160$ do Instituto Brasileiro do Meio Ambiente e dos Recursos Naturais Renováveis (Ibama), de 27 de abril de 2007, definiu coleção biológica como uma "coleção de material biológico testemunho constituída com o objetivo de gerar e subsidiar pesquisa científica ou tecnológica, bem como promover a cultura, a educação e a conservação do meio ambiente". Tal instrução registrou as coleções biológicas em diferentes tipologias: científica, didática, de serviço, de segurança nacional e particular, diferenciando-as por sua função social e especificidades decorrentes. As coleções científicas, alvo deste trabalho, são aquelas que, na definição dada pela IN (art. $3^{\circ}$, inciso I), mantêm o material biológico "devidamente tratado, conservado e documentado de acordo com normas e padrões que garantam a segurança, acessibilidade, qualidade, longevidade, integridade e interoperabilidade dos dados da coleção, pertencente à instituição científica com objetivo de subsidiar pesquisa científica ou tecnológica e a conservação ex situ". Boas referências sobre as coleções biológicas brasileiras são Peixoto (2003), que apresenta amplo panorama da situação das coleções, e MCT (2006a), ao propor um conjunto de diretrizes e ações prioritárias para que as coleções sejam apoiadas e gerenciadas para melhor atender ao avanço científico nacional e às demandas tecnológicas e de serviços do país.

O material biológico a que se refere a IN são "organismos ou partes desses" (art. 30, inciso X) preservados conforme normas e padrões que variam de acordo com o tipo de acervo (YOSHIDA, CHAMAS et al., 2005). Para servir de testemunho científico, cada espécime deve estar associado a um voucher, ficha catalográfica onde ficam registrados os dados da coleta do organismo - quem o coletou, quando e onde, qual a espécie, quem a identificou e quando, além de observações sobre o indivíduo coletado e o ambiente ao seu redor, entre outras (PEIXOTO e MORIM, 2003). Cada espécime de coleção biológica é, assim, um documento único como o original de uma obra de arte; seus vouchers são fonte primária para a certificação da diversidade de espécies de uma determinada região, base de reproducibilidade do método científico (LANE, EDWARDS et al., 2000).

A Convenção da Diversidade Biológica (CDB) encorajou as instituições depositárias de dados direta ou indiretamente relacionados à biodiversidade a disseminá-los pública e gratuitamente, e, no entardecer do século XX, no Brasil e no mundo, diversos provedores iniciaram projetos independentes de informatização de acervos que hoje estão amplamente disponíveis via internet (GONZALEZ, 2009). Surgiram então as redes interoperáveis, compartilhando dados primários como o GBIF, no mundo, ou o speciesLink, no Brasil, tornando possível proporem-se suprimir sistemas de indicadores para monitoramento da biodiversidade. O problema seguinte passou a ser a diversidade dos dados e o fato de que eles estão dispersos, e a solução foi criar padrões e protocolos para organizar a informação, de forma que dados de diferentes tipos e de fontes variadas pudessem ser combinados. Os protocolos utilizados para integrar os diferentes bancos de dados são o BioCase e o Distributed Generic Information Retrieval (DiGIR), também utilizado pela rede speciesLink. Um novo protocolo, o Access Protocol for Information Retrieval (Tapir), do Grupo de Trabalho Internacional em Bases de Dados Taxonômicos Taxonomic Databases Working Group (TDWG), está sendo implementado para integrar os dois outros hoje utilizados, o que demonstra claro esforço no sentido de evitar problemas na interoperabilidade dos sistemas, buscando facilitar ao máximo a integração de sistemas heterogêneos (LANE, EDWARDS et al., 2000; MAGALHÃES, SANTOS et al., 2001; CANHOS, SOUZA et al., 2004; GAIKWAD E CHAVAN, 2006).

Ci. Inf., Brasília, DF, v. 39 n. 1, p.33-50, jan./abr., 2010 
Análise das restrições de acesso a dados de espécies ameaçadas, previstas em políticas de coleções biológicas científicas brasileiras...

A estratégia brasileira para o tema vem sendo implementada modularmente e de forma distribuída, por meio de iniciativas que respondem a objetivos específicos, tais como o Projeto de Conservação e Uso sustentável da Diversidade Biológica Brasileira e o Programa Nacional de Diversidade Biológica. Na prática, porém, os mecanismos que assegurariam transparência e controle social sobre a efetividade da política ainda são incipientes (CAMPHORA, 2009). A té o momento, o país ainda não implementou sua estrutura de disseminação de dados e informações sobre sua biodiversidade, uma das maiores do planeta, ao contrário de vários países latino-americanos como a Colômbia e o México (CANHOS, CANHOS et al., 2006). Em agosto de 2008, o Ministério do Meio Ambiente (MMA) reinstituiu o Comitê de Assessoramento Técnico (CAT), por meio da Portaria n. ${ }^{\circ} 236$, de 8 de agosto de 2008, para avaliar e propor uma política de uso e divulgação da informação que viesse a nortear nossa estrutura, mas, até a data da redação deste trabalho, a discussão não havia chegado a termo. Há ainda entraves, aspectos delicados do problema, envolvendo propriedade intelectual ou soberania nacional, forças que atuam contra a livre circulação das informações (CORRÊA, SARAIVA et al., 2004).

A necessidade de um arcabouço de princípios, regras e orientações para todos os participantes do Programa de Pesquisa em Biodiversidade (PPBio) do Ministério de Ciência e Tecnologia (MCT), levou o Conselho Diretor da Coordenação Executiva do Programa a publicar, em meio eletrônico, uma minuta de política de acesso, uso e disseminação para os dados coletados e gerados no âmbito do Programa, no que diz respeito à "abrangência, à coleta, ao armazenamento, à propriedade, à autoria, ao compartilhamento, à citação, ao acesso e ao uso dos dados e das bases de dados" (MCT, 2006b). No presente trabalho, foi avaliado o princípio de "respeito à legislação brasileira pertinente" expresso nessa minuta de política do PPBio e naquelas que dela derivaram - as do Instituto Nacional de Pesquisas da Amazônia (Inpa), em Manaus, e do Museu Paraense Emílio Goeldi (Mpeg), em Belém, ambos institutos de pesquisas do MCT -, verificando-se a fundamentação legal das restrições de acesso aos dados de espécies ameaçadas de extinção, presente em todas elas.

\section{O DIREITO À INFORMAÇÃO AMBIENTAL}

Com a constatação do processo de degradação ambiental e da crescente consciência sobre os limites dos recursos naturais, a Conferência das Nações Unidas sobre Meio Ambiente Humano, realizada em Estocolmo, em junho de 1972, representou o marco de nascimento do direito ambiental internacional ao incorporar um novo olhar em relação ao direito à informação ambiental. Reconhecia ainda a importância da educação e da divulgação de informações para fundamentar as bases de uma opinião pública consciente de suas responsabilidades sociais e ambientais, equiparando pela primeira vez tal direito a outros já consagrados como fundamentais do homem:

Princípio n. ${ }^{\circ}$ 1: o ser humano tem o direito fundamental à liberdade, à igualdade e ao desfrute de condições de vida adequada em um meio cuja qualidade lhe permita levar uma vida digna e gozar de bem-estar, e tem a solene obrigação de proteger e melhorar esse meio para as gerações presentes e futuras.

A Declaração de Estocolmo viria a inspirar o legislador brasileiro na criação do art. $225 \mathrm{da}$ Constituição da República Federativa do Brasil de 1988. O meio ambiente é aí declarado "um bem de uso comum do povo e essencial à sadia qualidade de vida", cuja proteção exige uma participação tanto do cidadão quanto do Estado (FRANZON, 2003; OLIVEIRA, 2005). Sendo de interesse coletivo, os dados e as informações sobre o meio ambiente, tanto de titularidade privada como de domínio público, estão sujeitos à plena publicidade prevista no inciso XXXIII do art. $5^{\circ}$ da Carta Magna, aquele que trata dos direitos e garantias fundamentais da pessoa:

Todos têm o direito a receber dos órgãos públicos informações de seu interesse particular, ou de interesse coletivo ou geral, que serão prestadas no 
prazo da lei, sob pena de responsabilidade, ressalvadas aquelas cujo sigilo seja imprescindível à segurança da sociedade e do Estado.

Na Política Nacional do Meio Ambiente (Lei n. ${ }^{\circ}$ 6.938, de 31 de agosto de 1981), a formação de consciência pública sobre a necessidade de preservação da qualidade ambiental e do equilíbrio ecológico está relacionada à "divulgação de dados e informações ambientais" (art. $4^{\circ}, \mathrm{V}$ ), pois o legislador brasileiro entende que o livre acesso à informação é importante na defesa do meio ambiente: proporciona esclarecimento e instrução, e permite que os indivíduos estejam aptos a interferir no processo decisório, manifestando-se sobre os riscos que um impacto ambiental possa causar no presente e futuro, no meio em que vivem (TAVARES e FREIRE, 2003; BARROS, 2004b; SANTOS, 2005).

O mesmo entendimento está expresso no inciso II do art. $5^{\circ}$ da Lei n. ${ }^{\circ}$ 9.795, de 27 de abril de 1999 (Política Nacional de Educação Ambiental), que arrola a "garantia de democratização das informações ambientais" entre os objetivos fundamentais da educação ambiental, compreendida como "os processos por meio dos quais o indivíduo e a coletividade constroem valores sociais, conhecimentos, habilidades, atitudes e competências voltadas para a conservação do meio ambiente" (art. $1^{\circ}$ ).

No caso dos provedores de dados sobre a diversidade biológica, a Lei n. ${ }^{\circ}$ 10.650/2003 (Lei de Acesso à Informação Ambiental) obriga que os órgãos e as entidades da administração pública direta, indireta e fundacional, integrantes do Sistema Nacional do Meio Ambiente (Sisnama) permitam

O acesso público aos documentos, expedientes e processos administrativos que tratem de matéria ambiental, e a fornecer todas as informações ambientais que estejam sob sua guarda, especialmente as relativas à qualidade do meio ambiente, assegurandolhes, no entanto, qualquer sigilo protegido por lei" $\left(\operatorname{art} .2^{\circ}, \mathbb{S} 2^{\circ}\right)$.

A Lei n..$^{\circ}$ 7.347, de 24 de julho de 1985, que disciplina a ação civil pública de responsabilidade por danos causados ao meio ambiente, ao consumidor, a bens e direitos de valor artístico, estético, histórico, turístico e paisagístico, assegura ao interessado em ajuizar ação civil pública o direito de requerer às autoridades competentes as certidões e informações que julgar necessárias, a serem fornecidas em prazo de 15 dias. Somente nos casos em que a lei impuser sigilo, poderá ser negada certidão ou informação, hipótese em que a ação poderá ser proposta desacompanhada daqueles documentos, cabendo ao juiz requisitá-los. Nesse caso, não sendo o sigilo imposto diretamente por lei, poderá ser arguida a invalidade de atribuição por ato administrativo de grau de sigilo que visa a impedir o acesso à informação (SANTOS, 2005).

Pelo exposto, e conforme a Lei n. ${ }^{\circ} 10.650$, de 16 de abril de 2003 (Lei de Acesso à Informação Ambiental), os acervos das coleções científicas são "informações ambientais", estando assim sujeitos a dois direitos difusos: enquanto informações, ao Direito à Informação; e sendo de natureza ecológica, sob a tutela do direito ambiental. Daí advém, certamente, uma das dificuldades em se produzir uma política de acesso a dados ambientais, pois é difuso o direito que lida com bens comuns ao gênero humano, de "caráter transindividual, de natureza indivisível, de que são titulares pessoas indeterminadas e ligadas por circunstâncias de fato" (FRANZON, 2003; BARROS, 2004b).

Na redação de uma política de dados de coleções, portanto, há que se ter cautela ao tratar de restrições ao acesso a dados ambientais. A caracterização de determinado direito como fundamental, como o direito à informação pública, apresenta importante conseqüência processual prática, qual seja, a de submeter as normas jurídicas que regulamentam esse direito à possibilidade de controle não só de sua legalidade, mas também de sua constitucionalidade.

\section{ESPÉCIES AMEAÇADAS}

A unidade básica da biodiversidade é a espécie, de forma que seu número e sua identidade são indicadores para quem toma decisões acerca de quais áreas ou quais espécies conservar. Um produto 
Análise das restrições de acesso a dados de espécies ameaçadas, previstas em políticas de coleções biológicas científicas brasileiras...

prático que decorre da atividade de tomadores de decisão neste tema é a produção de listas de espécies ameaçadas de extinção que se tornam instrumento de políticas públicas do Ministério do Meio Ambiente (SCARANO, 2008), prestando-se como referencial para o combate à exploração ilegal, repressão à comercialização de plantas e animais silvestres e outras atividades conservacionistas. As listas nacionais foram adotadas como uma das metas da Estratégia Global para Conservação de Plantas (GSPC, sua sigla em inglês), uma iniciativa particularmente importante para a conservação de plantas com objetivos de médios e longos prazos que visam a interromper a atual e contínua diminuição da diversidade de plantas.

A Instrução Normativa MMA n. ${ }^{\circ}$ 6, de 23 de setembro de 2008, lista oficial das espécies ameaçadas da flora brasileira, define "ameaçadas de extinção" aquelas espécies "com alto risco de desaparecimento na natureza em futuro próximo, assim reconhecidas pelo Ministério do Meio Ambiente, com base em documentação científica disponível”. Em prazo máximo de cinco anos, a contar da publicação da IN n. ${ }^{\circ}$ 6, deverão ser desenvolvidos planos de ação com vistas à futura retirada de espécies da lista, elaborados e implementados com a participação de órgãos governamentais, da comunidade científica e da sociedade civil organizada (art. $5^{\circ}$ ). As espécies listadas são consideradas prioritárias para efeito de concessão de apoio financeiro à conservação pelo governo federal e deverão receber atenção especial no contexto da expansão e gestão do Sistema Nacional de Unidades de Conservação (SNUC), inclusive nos planos de manejo das Unidades de Conservação, bem como nos planos de conservação ex situ conduzidos no âmbito dos jardins botânicos e bancos de germoplasma brasileiros.

A realidade, no entanto, vem se mostrando muito mais lenta que as boas intenções da legislação. Biodiversidade é um sistema complexo por definição; reúne enorme variedade de formas, arranjos espaciais, processos e interações de sistemas biológicos nas mais diversas escalas e níveis de organização, de genes a espécies e desses a ecossistemas, com uma dinâmica que emerge das diferentes capacidades dos indivíduos de cada espécie em lidar com os recursos disponíveis. As interações espaço-temporais entre os diferentes indivíduos em um dado ambiente estabelecem uma organização em rede, com interações tipicamente não lineares, o que paradoxalmente confere ao sistema uma certa estabilidade (resiliência) em relação a perturbações ambientais. Tal estabilidade é mantida pela existência de vários atratores possíveis no sistema, que podem ser alcançados devido à plasticidade/flexibilidade dos indivíduos que formam a comunidade (SOUZA e BUCKERIDGE, 2004).

"Compreender a natureza assume contornos definidos em termos de possibilidades, não de certezas", diz Camphora (2009). Não é simples afirmar que uma espécie está ameaçada, e se está, sob que ameaças padece, em que categoria de ameaça ("vulnerável", "criticamente ameaçada", "extinta na natureza" etc.) ela deve ser classificada, seguindo qual critério, quais são as ameaças e as causas das ameaças, e como minimizar sua influência ou frequência, e quanto custa evitá-las, entre muitas perguntas sem respostas definitivas. E quanto maior a riqueza de espécies da flora de uma região, mais difícil se torna identificar quais delas estão ameaçadas, uma vez que a quantidade de informações científicas para cada uma tende a ser menor. $\mathrm{Na}$ maior parte das regiões de alta diversidade, as informações disponíveis sobre as espécies são muitas vezes incompletas e baseadas em esforços de coleta limitados. Surgem aí grandes dificuldades para se produzirem avaliações substanciais e definitivas relativas às chances de sobrevivência (GRAMMONT e CUARÓN, 2006).

Geralmente, a legislação se baseia em estabelecimento de limites arbitrariamente definidos, muitas vezes subjetivos ("populações reduzidas a nível crítico", "populações com reduções drásticas", "distribuição limitada"), a partir dos quais são mensurados escores para diferentes atributos, que somados indicam o grau de prioridade para determinada categoria ou o status de conservação (REGAN e COLYVAN, 1999). Nascimento e Magalhães (1998), no entanto, ao compararem listas de 
espécies ameaçadas (regionais, estaduais), no que diz respeito ao significado deste material para os diferentes processos de degradação ambiental, encontraram falta de padronização e de coerência na classificação das categorias de conservação, já que diferentes autores atribuem às mesmas espécies denominações distintas, o que indica variados estágios de degradação para determinada planta. Observaram ainda o conflito de informações sobre categorias adotadas em diferentes regiões geográficas. As informações conflitantes fazem das listas de conservação de espécies uma "ferramenta duvidosa".

Embora a presença de divergências nas atribuições das categorias de conservação apresentem limitações e discrepâncias, as listas de espécies ameaçadas devem ser entendidas, segundo os autores, como um veículo auxiliar para o desenvolvimento de atividades de preservação, sobretudo, no que se refere às espécies que sofrem exploração seletiva extrativista.

\section{O PONTO DE VISTA DA CIÊNCIA DA INFORMAÇÃO}

A discussão de acesso a dados biológicos tem vários pontos de contato com a ciência da informação, e ambas deveriam aproveitar suas experiências na questão. Ao analisar aspectos da legislação arquivística referentes ao direito de acesso, às restrições de uso e aos graus de sigilo documental, verifica-se que instituições como as depositárias de coleções científicas devem adotar procedimentos padronizados, que sistematizem os processos de produção, tramitação, uso e destinação dos documentos. Deveriam, como arquivos que são, ter como missão a "autenticidade" dos espécimes da coleção, criados e conservados de acordo com procedimentos regulares e rastreáveis; a "organicidade" e o "inter-relacionamento", dando aos espécimes elementos de coesão, espontâneos mas estruturados; e também a "unicidade", em que cada registro assume um lugar único na estrutura documental do grupo ao qual pertence; assim cópias de um registro como as duplicatas de um herbário, podem existir em um ou mais grupos de documentos, mas cada cópia é única em seu lugar, porque o complexo de suas relações com os demais registros do grupo é sempre único (FONSECA, 1999).

Há que se preservar a segurança dessas informações com medidas para monitorar seu acervo. O controle do acesso, nesses casos, irá requerer cadastro dos usuários, crachás de identificação, até mesmo restrição do espaço do acervo ao uso exclusivo dos funcionários. No caso de documentos digitais e eletrônicos, deve-se verificar a segurança e a confiabilidade do software utilizado, além de manter cópias de segurança para evitar a perda de informação. Em todos os casos, deve-se levar em consideração o grau de sigilo, qualquer que seja seu suporte, estando em consonância com a legislação (SFREDDO e FLORES, 2009).

Quando não há sigilo envolvido e todos estão, segundo a lei, autorizados, a ação de comunicação, conforme o pensamento de cientistas da informação, deveria ser oposta à preconizada pelas políticas em estudo. No final da década de 90, surgiram diversas manifestações em favor do acesso aberto ou acesso livre à informação científica, conseqüência das dificuldades encontradas em face da crise dos periódicos científicos. Buscaram-se alternativas de solução no sentido de manter o acesso a essas revistas por meio da formação de consórcios, criando-se portais de acesso às revistas eletrônicas com suporte das tecnologias da informação e comunicação e aplicação do modelo Open Archives $(\mathrm{OA})$, que estabelece um conjunto de padrões com vistas à interoperabilidade entre os repositórios digitais. O movimento vem ganhando adeptos em todo o mundo, por meio de declarações como a de Bethesda, de Budapeste, de Berlim e o manifesto brasileiro lançado pelo Instituto Brasileiro de Informação em Ciência e Tecnologia (KURAMOTO, 2006; ORTELLADO, 2008).

Embora o movimento tenha sido concebido como uma alternativa ante as dificuldades em ter acesso a publicações científicas, uma vez que os custos 
Análise das restrições de acesso a dados de espécies ameaçadas, previstas em políticas de coleções biológicas científicas brasileiras...

de assinatura dos periódicos científicos cresceram de forma exorbitante, a proposta não se restringe à publicação apenas de artigos, mas também do material suplementar resultado da pesquisa como é o caso dos vouchers em pesquisas sobre a biodiversidade (FUNK, HOCH et al., 2005). Essa definição foi utilizada pela Declaração de Berlim e pelo Manifesto Brasileiro de Apoio ao Acesso Livre à Informação Científica ${ }^{1}$, de 2005 , que preceitua que "contribuições em acesso livre incluem resultados de pesquisas científicas originais, dados não processados, metadados, fontes originais, representações digitais de materiais pictóricos, gráficos e material acadêmico multimídia”.

Em contraposição ao movimento de privatização de dados e informações, o conceito de data commons ou public commons também ganha evidência. Esse movimento promove o acesso aberto a dados e informações com base na experiência do desenvolvimento de softwares de código aberto (open source). O data commons procura incluir informações em domínio público e aquelas que permitem o acesso sem consentimento prévio (open access). Nesse caso, geralmente existe uma licença geral concedida com algumas restrições em relação à comercialização do dado ou da informação. $\mathrm{Na}$ comunidade conservacionista, também há um movimento denominado Conservation Commons, liderado pela União Internacional para a Conservação da Natureza e dos Recursos Naturais (IUCN), para tornar dados e conhecimento de acesso livre e aberto (CANHOS, CANHOS et al., 2006).

Além de livres, é necessário que informações ambientais estejam sistematizadas, atualizadas, disponíveis e integradas a bancos de dados federais, estaduais e municipais, bem como investimentos estatais na criação, na manutenção e no aparelhamento da estrutura física e humana dos centros de informação ambiental em todos os níveis, com a destinação de uma porcentagem do orçamento público a tais setores como uma

\footnotetext{
${ }^{1}$ http://kuramoto.files.wordpress.com/2008/09/manifesto-sobreo-acesso-livre-a-informacao-cientifica.pdf
}

ação de Estado e não apenas como paliativo de governo. Sem essas informações disponibilizadas de forma adequada e em tempo real, as autoridades podem adotar decisões inconsistentes com a realidade, gerando não apenas resultados distintos dos pretendidos como podendo produzir, nesse erro, perdas sociais e econômicas expressivas (GONÇALVES e JUNQUEIRA, 2004).

O Brasil, como país signatário da $\mathrm{CDB}$, deve apoiar ações que venham a dotar o governo e a sociedade de informações necessárias para o estabelecimento de prioridades que conduzam à conservação, à utilização sustentável e à repartição de benefícios da diversidade biológica brasileira. Para cumprir a tarefa, pode-se dizer que conta com um bom sistema de governança e um avançado código de leis sobre o meio ambiente, que tem como um dos princípios a livre circulação das informações ambientais em prol da qualidade do meio ambiente. Disto dependem todos os sistemas de indicadores que têm sido desenvolvidos em paralelo à crescente disponibilização eletrônica de dados e informações ambientais. A 2010 Biodiversity Indicators Partnership, por exemplo, expressa a Decisão VIII/15 da oitava Conferência das Partes (COP 8), de 2006, que estabeleceu um arcabouço de 22 indicadores principais em sete áreas focais, visando a atender três objetivos principais: gerar informações úteis sobre tendências na biodiversidade do planeta para apoiar tomada de decisão, garantir que tais indicadores sejam implementados e estejam disponíveis, bem como estabelecer conexões com as iniciativas regionais e nacionais, aumentando a efetividade do programa. O Sistema Global de Observação da Biodiversidade, GEO BON (SCHOLES, MACE et al., 2008), uma parceria internacional para auxiliar nos processos de coleta, análise, gerenciamento e divulgação de dados relacionados àqueles indicadores, é a principal implementação da Decisão VIII/15.

Outro sistema de indicadores desenvolvido neste período, este para as Américas, vem da Rede Interamericana de Informação sobre a Biodiversidade (IABIN, em inglês), que procurou 
reduzir ao máximo o número de indicadores, chegando a nove (IABIN, 2007). Há ainda muitas outras iniciativas internacionais para a conservação da biodiversidade de plantas, como o plano estratégico do Comitê de Plantas da Convenção sobre o Comércio Internacional da Fauna e da Flora Silvestre em Perigo de Extinção (Cites), o Programa Global para Espécies Exóticas Invasoras (Gisp), o Programa de Conservação de Plantas da Comissão de Sobrevivência das Espécies da IUCN (SSC/IUCN) e a Agenda Internacional para Conservação em Jardins Botânicos, cada uma delas dando tratamento a objetivos diferentes, mas muitas vezes recorrendo às mesmas variáveis. Sua indisponibilidade significa gargalo de uma grande rede que vem sendo tecida e que visa a entregar subsídios para uma economia mais justa e sustentável.

\section{Restrições no acesso a dados de espécies ameaçadas nas políticas do MCT}

No âmbito do PPBio, dados são

informações biológicas, ambientais, socioambientais ou espaciais adquiridas com recursos financeiros ou logísticos do PPBio - ou por ações amparadas por este. Podem ser caracterizadas como dados digitais ou conjuntos de dados armazenados e gerenciados por computadores; dados analógicos, oriundos de atividades do PPBio, ainda que não digitalizados, como anotações de campo, planilhas, cadernetas de coleta; e quaisquer relatórios ou mapas produzidos, em formato digital ou analógico, resultado da compilação, análise, reunião ou organização, utilizando como fonte conjuntos de dados do PPBio (MCT, 2006b).

Trata-se de uma definição condizente com o art. $2^{\circ}$ da Lei do Direito à Informação Ambiental quando ela faz menção à informação ambiental que esteja guardada "em meio escrito, visual, sonoro ou eletrônico". É importante destacá-lo aqui, pois qualquer restrição porventura imposta ao acesso a dados de repositórios públicos deveria, por esse princípio, estar prevista tanto para coleções arquivísticas quanto para as digitais, o que nem sempre se depreende nas políticas estudadas.
A importância do franqueamento de dados está expressa em alguns dos princípios que regem a política de dados do Inpa: "O conhecimento científico é incrementado por meio de ampla disseminação dos dados sobre a biodiversidade" e "A valorização dos dados como recurso institucional aumenta com o seu uso amplo e adequado, e diminui com o mau uso, má interpretação ou com desnecessárias restrições ao seu acesso" (INPA, 2006). A mesma política estabelece, porém, a figura dos "dados sensíveis", aqueles que, por "sua importância para a defesa dos interesses nacionais e a segurança do Estado e da sociedade, necessitam de medidas especiais de salvaguarda" (INPA, 2006). Apoia-se aqui, provavelmente, no inciso XXXIII do art. $5^{\circ}$ da Constituição de 1988, que preceitua sigilo para informações imprescindíveis "à segurança da sociedade e do Estado", isto é, quando o fornecimento da informação possa resultar em prejuízo ou lesão a direito de qualquer natureza a particular, coletivo ou ao Estado (FRANZON, 2003).

Ainda que se considere também o parágrafo $1^{\circ}$ do art. 23 da Lei n. ${ }^{\circ}$ 8.159, de 8 de janeiro de 1991 (Lei do Acesso e do Sigilo dos Documentos Públicos), que acrescentou à lista de informações sigilosas os documentos que resguardam a "inviolabilidade da intimidade, da vida privada, da honra e da imagem das pessoas", ou seja, o direito à privacidade humana, observa-se que o material preservado em coleções biológicas científicas a que se referem as políticas do MCT não se enquadra em nenhuma das categorias de sigilo previstas, nem mesmo a que remete à segurança nacional, como documentos relativos a "aspectos da política interna, questões fiscais e cambiais, moeda e crédito público" (FONSECA, 1999), todos muito diferentes do tipo de documento depositado em herbários e museus. Estocar cepas de organismos que possam sustentar ameaças como, por exemplo, o bioterrorismo - que após o 11 de Setembro de 2001 ficaram mais evidentes (YOSHIDA, CHAMAS et al., 2005) - não é função social das coleções biológicas científicas, e, sim, daquelas classificadas pela Instrução Normativa n. ${ }^{\circ}$ 160/2007, do Ibama, como "de segurança nacional", compostas de 
Análise das restrições de acesso a dados de espécies ameaçadas, previstas em políticas de coleções biológicas científicas brasileiras...

acervos múltiplos, vivos, (...) com representatividade do conjunto gênico de diferentes espécies de importância estratégica que promovam a autossuficiência e a segurança interna da nação, considerando fatores econômicos, sociais, populacionais, ambientais e tecnológicos.

A minuta de política do PPBio define os dados sensíveis como "dados preliminares ou consolidados que, se liberados ao acesso público, possam resultar em efeito adverso ao local e/ou às comunidades de origem da mesma [espécie] e por isso, passível de restrição" (MCT, 2006b), citando como exemplo a localização exata de espécies que estejam na lista de espécies biológicas ameaçadas de extinção - seja por seu potencial econômico, comercial ou mesmo por sua raridade. Trata-se de uma precaução comum entre curadores de coleções (HOUSE, 2002), consideram que a divulgação contribuiria para sua destruição, uma vez que tal ameaça estaria, muitas vezes, relacionada à grande procura por essas espécies. A preocupação com o uso comercial é expressa, ademais, nos seguintes termos: "Os dados gerados no âmbito do PPBio podem ter interesse comercial e seu uso pode gerar conseqüências econômicas e ambientais", e resolve que "o acesso e uso com intenção comercial (...) deverá ocorrer mediante a celebração de contrato entre as partes interessadas, observada a legislação pertinente e as disposições desta Política" (MCT, 2006b). Na política do Inpa consta que "nenhum dado das coleções (...) poderá ser utilizado com intensão comercial sem autorização expressa do representante legal da instituição, sendo condição para tal autorização que eventuais direitos autorais sejam atribuídos ao Inpa” (INPA, 2006).

Se não restam dúvidas de que os direitos autorais envolvidos nas publicações devem ser protegidos, o mesmo não se pode dizer sobre as bases de dados, pois não é claro a que autores se referem. $O$ art. $7^{\circ}$ da Lei n. ${ }^{\circ}$ 9.610/1998 (Lei de Direitos Autorais, LDA) indica quais obras intelectuais são protegidas pelos direitos autorais: são as "criações do espírito", expressas por qualquer meio ou fixadas em qualquer suporte, tangível ou intangível, conhecido ou que se invente no futuro, em que se destacam, para os propósitos deste trabalho, "os textos de obras literárias, artísticas ou científicas" (inciso I), "as conferências, alocuções, sermões e outras obras da mesma natureza" (inciso II) e "as coletâneas ou compilações, antologias, enciclopédias, dicionários, bases de dados e outras obras, que, por sua seleção, organização ou disposição de seu conteúdo, constituam uma criação intelectual" (inciso XIII), entre outras de cunho mais artístico, além de projetos de arquitetura e programas de computador. Portanto, para que uma obra seja protegida pela lei, é fundamental que seja uma criação do espírito, o que não parece ser o caso dos espécimes de coleções biológicas científicas.

Algumas atividades relacionadas às coleções, como a transcrição ou digitação dos dados de coleções e a fotografia de espécimes, consomem recursos financeiros das instituições ou projetos científicos, e, por isso, eventualmente cogitam um tratamento dispensado a autores, mas, também por não envolverem a criação do espírito, não podem ser considerados autorais e, portanto, não estão protegidos pela LDA. Pelo mesmo motivo não se podem considerar autorais as bases de dados (as coleções propriamente ditas ou suas extensões) por conterem informações de domínio público, que apenas exigem esforços na reunião e catalogação (PAIVA, 2005). Mas e quanto ao trabalho de obtenção e verificação do material? Trata-se de um esforço custoso, realizado ou coordenado por especialistas, cuja formação pode consumir décadas de estudos até torná-los capazes de organizar uma base de dados primários adequada à metodologia científica para a geração de um novo conhecimento. Estaria esse esforço protegido pelas leis brasileiras como gostariam muitos cientistas?

A proteção a bases de dados conferida pela LDA limita-se à forma de expressão da estrutura da base (art. 87), e não de cada item individualmente. Isto quer dizer que, atualmente, é possível que terceiros utilizem um simples dado sem a necessidade de autorização (PIMENTA, 1998). No setor privado, 
a proteção de bases de dados de conteúdos informativos se dá pelas normas que regulam os contratos e os segredos de negócios, de forma que, ocorrendo a quebra de sigilo ou utilização indevida do banco de dados, o lesado tenha o direito de ir a juízo buscar indenização com base no Código Civil, alegando inadimplemento contratual (SILVA, 2008). O setor público, no entanto, só pode fazer o que é determinado por lei, diferentemente do setor privado, que pode fazer tudo que a lei não proíbe (LIMA, 2007). Não cabe, assim, a uma política institucional sobrepor-se a leis federais, estabelecendo restrição ao acesso "aos dados ainda não divulgados" (MCT, 2006b) e a "registros essenciais para pesquisas em andamento" (INPA, 2006). A rigor, pela legislação ambiental brasileira, todos os dados de todos os espécimes e suas extenções lógicas devem estar disponíveis ao público, tão logo sejam tombados em uma coleção.

No exterior, nota-se a preocupação em proteger as bases de dados, sem que isso represente atraso e concentração de informações. Na Europa, EUA e também no México, uma tendência vem modelando um regime particular, sui generis, de propriedade intelectual - uma proteção jurídica às bases de dados que não constituam um conteúdo necessariamente criativo: protege-se o conteúdo por ele mesmo, objetivando a salvaguarda do investimento substancial, em tempo e dinheiro, da organização que despendeu esforços na coleta e no armazenamento de informações. Três grandes correntes incentivam, desde 1996, a aplicação desta teoria: a Diretiva 96/9/CE do Parlamento Europeu e do Conselho, o Database Investment and Anti Piracy Act (EUA) e a Proposta de Tratado sobre Base de Dados da Organização Mundial de Propriedade Intelectual (OMPI), que veio harmonizar as duas primeiras e prevê que o criador tem o direito de autorizar ou proibir a extração ou utilização do conteúdo da base de dados, garantindo seu uso por um período de 15 a 25 anos (KEUNECKE, 2002; BORGES, 2008; CORRÊA e SANTOS, 2008).
Embora compreensíveis, as justificativas para a restrição ao acesso a dados ambientais vão claramente no sentido oposto ao espírito do direito à informação ambiental como se procurou mostrar. De fato, não há, no direito brasileiro, nenhum diploma que sustente ou incentive restrições de acesso a dados de espécies pelo fato de ela estar ameaçada. Mesmo o acesso por meio de autorização, que também consta na política do Inpa, é de legalidade questionável, pois o direito difuso, como o que rege o meio ambiente, é de caráter transindividual, de natureza indivisível, e deve ser direcionada a todas as pessoas que se disponham a recebê-la, sem que se possa individualizar e dividir qual informação será difundida para este indivíduo e qual para aquele. Todos os titulares estão ligados pela circunstância de fato de serem receptores da mesma publicidade (SANTOS, 2000; BARROS, 2004b; OLIVEIRA, 2005). Daí o texto da Lei n. ${ }^{\circ} 10.650 / 2003$, de Acesso à Informação Ambiental: "Qualquer indivíduo, independentemente da comprovação de interesse específico, terá acesso às informações de que trata esta Lei (...)" ( $\mathbb{S} 1^{\circ}$ do art. $\left.2^{\circ}\right)$.

Por trás das restrições das políticas do MCT esconde-se outro grande temor no que se refere à biodiversidade brasileira: a chamada "biopirataria". Supõe-se que os dados e as informações das coleções biológicas sejam usados indevidamente, ou descontroladamente, na prospecção para a indústria sem a devida repartição de benefícios. Nas políticas, tal preocupação está expressa assim: "são considerados sensíveis (...) dados de espécie que possa ser roubada ou traficada por sua raridade ou valor econômico (considerando sua potencialidade: como fornecedora de produtos que venham a ser utilizados na indústria farmacêutica ou química; como agente de controle biológico; entre outras)" e "o acesso e uso (...) de forma que possa resultar na geração de produtos ou processos passíveis de exploração econômica deverá ocorrer mediante a celebração de contrato entre as partes interessadas" (MCT, 2006b). 
Análise das restrições de acesso a dados de espécies ameaçadas, previstas em políticas de coleções biológicas científicas brasileiras...

Mas a lei n. ${ }^{\circ}$ 9.279/96, ou Lei da Propriedade Industrial (LPI), parece também não dar tutela às coleções biológicas científicas. $\mathrm{O}$ art. $2^{\circ}$ desta lei arrola, entre as formas aceitas de proteção dos direitos relativos à propriedade industrial, considerado o seu interesse social e o desenvolvimento tecnológico e econômico do país, duas que poderiam apoiar as restrições previstas nas políticas de dados estudadas: a concessão de patentes de invenção e de modelo de utilidade (inciso I) e a repressão à concorrência desleal (inciso V). Porém, não são patenteáveis "o todo ou parte de seres vivos naturais e materiais biológicos encontrados na natureza, ou ainda que dela isolados, inclusive o genoma ou germoplasma de qualquer ser vivo natural e os processos biológicos naturais" (art. 10, inciso IX da LPI). A semente silvestre, por exemplo de espécime de coleção científica, não é objeto de proteção, mas, sim, o cultivar (GONÇALVES e JUNQUEIRA, 2004) axiomático exemplar de uma coleção "de serviço", aquelas que, segundo a Instrução Normativa n. ${ }^{\circ}$ 160/2007, reúnem "material biológico certificado devidamente tratado e conservado de acordo com normas e padrões que garantam a autenticidade, pureza e viabilidade, bem como a segurança e o rastreamento do material e das informações associadas".

Quanto à concorrência desleal, diz o art. 195 da LPI que comete crime quem divulga, explora ou utilizase, sem autorização, de

conhecimentos, informações ou dados confidenciais, utilizáveis na indústria, comércio ou prestação de serviços, excluídos aqueles que sejam de conhecimento público ou que sejam evidentes para um técnico no assunto, a que teve acesso mediante relação contratual ou empregatícia, mesmo após o término do contrato" (inciso XI)

ou de "resultados de testes ou outros dados não divulgados, cuja elaboração envolva esforço considerável e que tenham sido apresentados a entidades governamentais como condição para aprovar a comercialização de produtos" (inciso XIV). As coleções biológicas, portanto, ao não arquivar documentos "confidenciais" e nem apresentar seus espécimes “como condição para aprovação...", não estão sob o império da concorrência desleal.

Nas políticas estudadas, geralmente são considerados sensíveis no que tange à propriedade industrial outro conjunto de dados, além dos biogeográficos já citados (espécie e local de ocorrência): as informações obtidas em campo junto a comunidades tradicionais sobre os usos que elas fazem do ser vivo coletado. Sobre esta informação, o art. $9^{\circ}$, inciso II, alínea b da Medida Provisória n. ${ }^{\circ}$ 2.186-16, de 23 de agosto de 2001 - que dispõe sobre "o acesso ao patrimônio genético, a proteção e o acesso ao conhecimento tradicional associado, a repartição de benefícios e o acesso à tecnologia e transferência de tecnologia para sua conservação e utilização" - parece ter criado o único sigilo legal associável aos espécimes das coleções biológicas científicas:

À comunidade indígena e à comunidade local que criam, desenvolvem, detêm ou conservam conhecimento tradicional associado ao patrimônio genético, é garantido o direito de impedir terceiros não autorizados de divulgar, transmitir ou retransmitir dados ou informações que integram ou constituem conhecimento tradicional associado.

A MP define "conhecimento tradicional associado" como a "obtenção de informação sobre conhecimento ou prática individual ou coletiva, associada ao patrimônio genético, de comunidade indígena ou de comunidade local, para fins de pesquisa científica, desenvolvimento tecnológico ou bioprospecção, visando sua aplicação industrial ou de outra natureza". Informações sobre uso de seres vivos em práticas terapêuticas tradicionais, por exemplo, têm sido consideradas conhecimento tradicional adquirido, e proporcionam uma abordagem rápida e barata para identificação de produtos farmacológicos com mecanismos de ação pouco ou sequer conhecidos (ELISABETSKY, 2003; ALBUQUERQUE e HANAZAKI, 2006). Uma questão ainda sem resposta é: informações oriundas de acesso ao conhecimento tradicional podem ou não ser divulgadas por meio de um 
portal que recolhe repositórios digitais de coleções biológicas e os divulga integradamente como o speciesLink $k^{2}$ ? Pelo texto da MP, uma informação não poderia ser retransmitida a não ser que a autorização dada pelo detentor do conhecimento tradicional expressamente alcançasse o retransmissor, já que se trataria de um terceiro não autorizado "retransmitindo" a mesma informação, ainda que o coletor tivesse tal autorização.

A MP não tipificou, no entanto, a exploração ilegal desses recursos como crime, nem estabeleceu penalidades para os infratores (que acabam sendo punidos, quando muito, como traficantes). Desde 2003, o Comitê de Gestão do Patrimônio Genético, órgão do Ministério do Meio Ambiente, criado para regular as pesquisas com a biodiversidade, discute um projeto de lei definitivo sobre o assunto. A ideia é estabelecer regras para beneficiar as comunidades com o uso comercial de seus conhecimentos e definir a biopirataria como crime, impondo punições. Até que se defina com clareza em lei a natureza jurídica do bem "conhecimento tradicional associado", ele permanece sendo objeto de debate entre juristas. A interpretação que tem prevalecido é a de que se trata de um bem de relevante interesse público ou de uso comum do povo, compreendendo-se que pertence à coletividade, cabendo à administração pública apenas a sua guarda e gestão sem retirar o direito dos titulares das áreas sobre os organismos que ali existem (AZEVEDO, 2005).

Não restam dúvidas de que os recursos naturais brasileiros sejam fonte potencial para a criação de novos produtos, para a indústria farmacêutica, química, de cosméticos e de alimentos. E que, até alguns anos atrás, este patrimônio vinha sendo "explorado" mormente por países desenvolvidos. Há casos de espécies nativas - plantas, animais e micro-organismos - que deram origem a produtos patenteados no exterior e explorados comercialmente (BARROS e BELAS, 2004). Mas os reclames da soberania nacional são argumentos fortes o suficiente para inibir um direito fundamental

${ }^{2}$ http://splink.cria.org.br/ não só de brasileiros, mas de todo ser humano? Sobre a questão, o Greenpeace assim se coloca:

O caráter confidencial das informações comerciais não deve sobrepor-se ao interesse público de conhecer os riscos nem às responsabilidades associadas aos resultados de ações corporativas, seja na forma de subprodutos poluentes ou do produto propriamente dito. Assim que o produto entra em domínio público, segredos comerciais não devem ser motivo para restrição de acesso a informações relevantes ao meio ambiente e à saúde. A responsabilidade corporativa deve ser promovida por meio do relato da situação ambiental da empresa, que forneça um relato claro, abrangente e público sobre os impactos ambientais e sociais das atividades ${ }^{3}$.

A Organização de Cooperação e de Desenvolvimento Econômico (OCDE) parece concordar com a posição do Greenpeace e vai além. Na reunião do Comitê de Política para Ciência e Tecnologia, em 2004, a organização discutiu a questão de patentes e o acesso aberto a dados de pesquisa financiada com recursos públicos. Entre outros pontos, foi assegurado o acesso amplo ao conhecimento obtido por meio de pesquisas com financiamento público, e os países deverão assegurar que o sistema patentário não prejudique o acesso ao conhecimento, não reduza os incentivos para disseminar conhecimentos nem impeça a inovação.

Os ministros de países membros da OCDE reconhecem que, ao promover o acesso aberto e amplo a dados de pesquisa, estarão melhorando a qualidade e a produtividade dos sistemas científicos do mundo. Assim, adotaram a Declaração de Acesso a Dados de Pesquisa de Financiamento Público (Declaration on Access to Research Data From Public Funding), em que admitem ter como compromisso trabalhar para o estabelecimento de regimes de acesso a dados digitais de pesquisas financiadas com recursos públicos, seguindo os princípios de equilíbrio (considerando as motivações do acesso aberto e da proteção aos interesses sociais, científicos e econômicos), transparência, conformidade legal,

3 Levantamento intitulado "Crimes Ambientais no Brasil" (apud Vilas Boas, 2004).

Ci. Inf., Brasília, DF, v. 39 n. 1, p.33-50, jan./abr., 2010 
Análise das restrições de acesso a dados de espécies ameaçadas, previstas em políticas de coleções biológicas científicas brasileiras...

responsabilidade formal, profissionalismo, proteção à propriedade intelectual, interoperabilidade, qualidade e segurança, eficiência e responsabilidade. Essa posição da OCDE é considerada importante, e parece reverter a tendência de "privatização" dos dados científicos (MCT, 2006a).

\section{DISCUSSÃO}

O conhecimento produzido por especialistas em espécies ameaçadas, muitas vezes os únicos agentes públicos a conhecê-las in situ, desempenham papel cada vez mais importante na formulação de políticas públicas nos mais diversos países (VIVACQUA e VIEIRA, 2005). O princípio jurídico da "prevenção" ou "precaução" determina que as normas de direito ambiental devem sempre se orientar para o fato de que é necessário que o meio ambiente seja preservado e protegido como patrimônio público, e é aplicável tanto em situações em que há certeza sobre os riscos de danos ambientais, quanto às situações nas quais existem dúvidas e incertezas (LISBOA e BARROS, 2008). O artigo 225, $\$ 1^{\circ}$, inciso IV da Constituição Federal impôs ao poder público a obrigação de "exigir, na forma da lei, para instalação de obra ou atividade potencialmente causadora de significativa degradação do meio ambiente, estudo prévio de impacto ambiental, a que se dará publicidade". A ocorrência de dada espécie ameaçada em um local para onde se planeje algum grande empreendimento industrial, imobiliário ou mesmo agrícola pode, por vezes, implicar a total inviabilidade legal do empreendimento (SCARANO, 2008).

A aplicação do artigo constitucional, que ainda está por ser conquistada (BARROS, 2004a), pode provocar transtornos políticos, e um bom exemplo disso foi dado pelo próprio presidente Lula:

A gente está fazendo um grande viaduto no Rio Grande do Sul, ligando a BR-101, que vai trazer muita gente da Argentina para o Brasil e muita gente do Brasil para a Argentina. Esse túnel tem mil e poucos metros, e encontraram do lado do túnel uma perereca. Todo mundo aqui sabe o que é uma perereca. Pois bem, aí resolveram fazer um estudo para saber se aquela perereca estava em extinção. Aí teve que contratar gente para procurar perereca, e procure perereca, e procure perereca... Sabem quantos meses demorou para descobrir que a perereca não estava em extinção? Sete meses, a obra parada. Eu espero que aqui no Acre não apareça nenhuma perereca na ponte do Rio Juruá. Não é possível (O Globo, 1/5/2009).

Em tese, restrições ao acesso livre a dados podem até prejudicar as espécies. A Lei n. ${ }^{\circ}$ 9.393/1996, que disciplina o Imposto Territorial Rural (ITR), por exemplo, exclui da área tributável as áreas de preservação permanente e de reserva legal previstas na Lei n. ${ }^{\circ} 4.771 / 1965$, e as de interesse ecológico para a proteção de ecossistemas, assim declaradas mediante ato do órgão competente, federal ou estadual - o que pode se tornar um significativo decréscimo no valor do imposto (PIRES, HOSOKAWA et al., 2001). Mas para que proprietários conheçam o valor ambiental de suas terras, para que a eles chegue a informação de que em suas propriedades ocorrem espécies da flora e da fauna que estão desaparecendo, é preciso construir um ambiente de ampla e livre circulação das informações (FRANZON, 2003) e não de restrições.

A legislação não parece atribuir à instituição mantenedora de coleção biológica científica poder legislativo sobre um bem comum ao gênero humano - um meio ambiente ecologicamente equilibrado -, mas sim contribuir com o zelo a esse bem, como membro de um coletivo, apelando aos meios judiciais de tutela a exemplo da ação popular, da ação civil pública, do mandado de segurança coletivo e do mandado de injunção, sempre que estiver ciente de práticas ilegais degradadoras do meio ambiente e da diversidade biológica que contém (OLIVEIRA, 2005; SANTOS e GÓES, 2006).

Como princípio, as imposições contra atos lesivos ao meio ambiente procuram onerar o agente causador com gravame de valor superior ao valor negativo do ato lesivo, de tal sorte que iniba todos e quaisquer atos similares futuros. 
Mas a legislação procura oferecer, em paralelo, uma agenda de educação e amadurecimento da sociedade brasileira quanto à importância do meio ambiente. São mecanismos econômicos, como a graduação de tributos, principalmente os extrafiscais - que atendem, como o ITR e o ICMS Ecológico, a fins outros que não exclusivamente a arrecadação, mas, geralmente, à correção de situações sociais indesejadas e à condução de estímulos. Incentivamse atividades não poluidoras e desestimulam-se as nocivas, produzindo um ambiente institucional e econômico no qual os serviços ambientais prestados pelos ecossistemas nativos passem a ser valorizados e remunerados (RIVA, FONSECA et al., 2007). Não se deve esquecer, porém, que o homem está nesta equação e, nesse sentido, encontram-se em discussão os projetos de Lei n. ${ }^{\circ} 306$, n. $^{\circ} 4.569$ e n. ${ }^{\circ} 4.751$, que preveem a possibilidade de criação de condições para que as pessoas gozem dos recursos nos locais onde residam.

O que se observa, no que se refere à biopirataria, é a ausência de uma legislação que defina as regras de usos dos nossos próprios recursos naturais e de estruturas físicas e financeiras para o desenvolvimento das pesquisas necessárias para que o povo brasileiro se beneficie delas. Há que se regular a questão internacionalmente, uma vez que muitos países, especialmente os desenvolvidos, não reconhecem o direito das nações sobre o patrimônio genético nativo, o que, na prática, incentiva suas empresas a continuarem com a biopirataria (MASCARENHAS, 2004; CARDIN, 2006). Devemos lembrar, entretanto, que a esmagadora maioria dos vegetais cultivados no Brasil - café, laranja, soja, manga, só para citar alguns exemplos - são materiais genéticos oriundos de ecossistemas localizados noutros países (GONÇALVES e JUNQUEIRA, 2004).

A sociedade brasileira vem emitindo sinais de que pretende abandonar a cômoda situação dos países pobres expoliados pelos países mais ricos por meio de um caminho mais maduro, que evita atalhos como a restrição ao acesso de dados ambientais. Sua macroestratégia está clara na Política Nacional do Meio Ambiente,
Lei n. ${ }^{\circ}$ 6.938, de 31 de agosto de 1981, que nos artigos $2^{\circ}, 4^{\circ}$ e $9^{\circ}$ estabeleceu as seguintes obrigações do poder público relativas à coleta e disseminação de informações sobre o meio ambiente: (a) garantir, por meio do Sistema Nacional de informações sobre o Meio Ambiente (Sinima), a prestação de informações relativas ao meio ambiente; (b) elaborar Relatório de Qualidade de Meio Ambiente (RQMA), um acompanhamento do estado da qualidade ambiental, a ser divulgado anualmente pelo Instituto Brasileiro do Meio Ambiente e dos Recursos Naturais Renováveis (Ibama), e (c) promover a educação ambiental em todos os nível de ensino, inclusive educação da comunidade, objetivando capacitá-la para participação ativa na defesa do meio ambiente.

Em relação ao comércio exterior, há os decretos legislativos n. ${ }^{\text {ss }} 02$ e 03 de 1994, que disciplinam a Convenção da Diversidade Biológica, e o Decreto n. ${ }^{\circ} 76.623$ de 1975 , que trata da Convenção sobre o Comércio Internacional de Espécies Ameaçadas de Fauna e Flora Silvestres (Cites), que buscam mecanismos que mantenham a sustentabilidade de reservas legais além de protegê-las do comércio internacional. O Brasil é signatário ainda de três acordos relativos a patentes: a Convenção da União de Paris para a Proteção da Propriedade Industrial (CUP), o Tratado de Cooperação em Matéria de Patentes (PCT) e o Acordo Sobre os Aspectos dos Direitos de Propriedade Intelectual Relacionados ao Comércio (TRIPA). Os membros deste último estão obrigados, pelo artigo 39 do acordo, a proteger, contra o uso comercial desleal, as informações confidenciais, ali entendidas como aquelas que (a) sejam secretas, isto é, não conhecidas em geral nem facilmente acessíveis a pessoas de círculos que normalmente lidam com o tipo de informação em questão, (b) tenham valor comercial por serem secretas e (c) tenham sido objeto de precauções razoáveis, nas circunstâncias, pela pessoa legalmente em controle da informação, para mantê-la secreta. Em contrapartida, exigese dos detentores de informações confidenciais a apresentação de resultados de testes ou outros dados não divulgados, cuja elaboração envolva 
Análise das restrições de acesso a dados de espécies ameaçadas, previstas em políticas de coleções biológicas científicas brasileiras...

esforço considerável como condição para aprovar a comercialização de produtos farmacêuticos ou de produtos agroquímicos que utilizem novas entidades químicas (PARANAGUÁ, 2008)

A implementação em larga escala dos mercados de serviços ambientais, que ainda tem muito a avançar, pode ter impacto substancial sobre o meio ambiente, padrões regionais de renda e sobre as próprias possibilidades de desenvolvimento regional. Sob o ponto de vista político, já se constatou que, sem o apoio das comunidades locais, grande parte das ações conservacionistas e preservacionistas tem efeito oposto à real conservação dos hábitats e dos recursos naturais (DIEGUES, ARRUDA et al., 2000) - o que é uma ótima notícia quando se pensa em política de inclusão social e incentivo à inovação.

\section{CONCLUSÕES}

O fato de uma espécie estar ameaçada guarda pouca relação com a "importância para a defesa dos interesses nacionais e a segurança do Estado e da sociedade", que caracterizaria o sigilo constitucional. Ao menos até o momento, a extinção de espécies biológicas ainda não é considerada, no Brasil, uma ameaça à nação. No entender deste trabalho, as políticas de coleções aqui abordadas ferem o principal de seus princípios fundamentais, o "respeito à legislação brasileira pertinente" no que se refere ao direito à informação ambiental.

Tal constatação se coloca como mais um exemplo, já observado antes (BARROS, 2004a; CANHOS, CANHOS et al., 2006), de que, embora a disseminação de dados e informações on-line esteja presente nos últimos planos plurianuais de todos os ministérios que, transversalmente, geram dados sobre o meio ambiente (MCT, MMA, Mistério da Educação, além de IBGE, Fiocruz etc.), não há uma política clara e explícita de criação de infraestrutura compartilhada para disseminar os resultados dos programas, nem uma política específica para "coleções de dados" (bancos de dados, sistemas de informação etc.). Em programas, geradores de dados e informações sobre espécies e espécimes - Programa Antártico Brasileiro, Sociedade da Informação, Xingó, Instituto do Milênio, alguns exemplos nem sempre citados como tal - não encontramos sistemas de informação nem sequer bancos de dados de acesso público. Quando muito há um livro, alguma publicação ou planilha.

Sugere-se que as políticas estudadas sejam revistas com base em uma discussão mais profunda sobre essa e outras restrições, em colegiado de nível nacional, pois a questão é complexa e interessa a todos os brasileiros. Que tal colegiado envolva não somente cientistas (biólogos, arquivistas, museólogos) e gestores de ministérios, cuja participação é fundamental, mas também advogados especialistas no assunto e representantes das redes de informação e informática do governo federal, já que o tema também diz respeito a programas de interoperabilidade, segurança e compliance (conformidade com a legislação) dos sistemas de governo.

Sugere-se ainda que instrumentos como as políticas estudadas caminhem em direção diametralmente oposta ao restringimento; que aproveitem o ambiente jurídico, social e tecnologicamente propício para incentivar ampla integração e comunicação de dados, informações e indicadores disponíveis sobre o meio ambiente, e mais que o direito à informação, façam valer pro ativamente o direito do cidadão de "ser informado". Que o proprietário saiba o valor ecológico de suas propriedades e as suas responsabilidades perante tal patrimônio, mas que seja bem informado sobre os benefícios advindos de sua conservação previstos em lei. Se é um princípio que norteia a liberdade de imprensa e a transparência dos gastos públicos, por que não valeria também para a saúde do meio ambiente?

\section{AGRADECIMENTOS}

A Ana Lucia Camphora, Ariane Peixoto, Claudia Barros, Eduardo Dalcin, Flavio Kubota, Gustavo Martinelli e Ione Egler, pelas contribuições ao texto.

Artigo submetido em 30/03/2009 e aceito em 10/06/2010. 


\section{REFERÊNCIAS}

ALBUQUERQUE, U. P. D.; HANAZAKI, N. As pesquisas etnodirigidas na descoberta de novos fármacos de interesse médico e farmacêutico: fragilidades e pespectivas. Revista Brasileira de Farmacognosia, João Pessoa, v.16, p. 678-689, 2006. Suplemento.

AZEVEDO, C. M. A. A regulamentação do acesso aos recursos genéticos e aos conhecimentos tradicionais associados no Brasil. Biota Neotropica, v.5, n.1, p. 1-9, 2005.

BARROS, B. D. S.; BELAS, C. A. (Coord.). Curso de introdução a Propriedade Intelectual. Belém: NPI/MPEG, 2004. 79 p.

BARROS, L. V. A efetividade do direito à informação ambiental. 2004. 230 f. Dissertação (Mestrado em Política e Gestão Ambiental) - Centro de Desenvolvimento Sustentável, Universidade de Brasília, Brasília, 2004.

- A nova lei do direito à informação ambiental. Revista SPEI, Curitiba, v.5, n.1, p. 8-13, 2004.

BORGES, Maria Manuel. A propriedade intelectual: do direito privado ao bem público. Observatorio (OBS*) Journal, Coimbra, v. 2, n. 2, p. 225-244, 2008.

BOWKER, G. C. Work and information practices in the sciences of biodiversity. In: INTERNATIONAL CONFERENCE ON VERY LARGE DATA BASES, 26., 2000, Cairo. Proceedings... Cairo: Morgan Kaufmann, 2000. p. 693-696.

CAMPHORA, A. L. Governança e custos de transação na gestão da compensação ambiental criada pelo Art. 36 do SNUC. In: CONGRESSO BRASILEIRO DE SOCIOLOGIA, 14., 2009, Rio de Janeiro. Anais... Rio de Janeiro: SBS, 2009. 20 p.

CANHOS, D. A. L. et al. Coleções biológicas e sistemas de informação. In: MINISTÉRIO DA CIÊNCIA E TECNOLOGIA. Diretrizes e estratégias para a modernização de coleções biológicas brasileiras e a consolidação de sistemas integrados de informação sobre biodiversidade. Brasília: CGEE/MCT, 2006. p. 241-314. (Coleções biológicas e sistemas de informação).

CANHOS, V. P. Informática para biodiversidade: padrões, protocolos e ferramentas. Ciência e Cultura, São Paulo. v.55, n.2, p. 45-47, 2003.

CANHOS, V. P. et al. Global biodiversity informatics: setting the scene for a new world of ecological modeling. Biodiversity Informatics, v.1, p. 1-13, 2004.

CARDIN, V. S. G. Das plantas medicinais e a biopirataria. In: CONGRESSO NACIONAL DE PÓS GRADUAÇÃO DE DIREITO (CONPEDI), 15., 2006, Manaus. Anais... Manaus, 2006. p. 345-375.
CORRÊA, A. E.; SANTOS, A. M. D. Biotecnologia, direito e política: a propriedade intelectual e a apropriação do humano como informação. Ciência e Cultura, São Paulo, v.60, n.1, p. 29-32, 2008.

CORRÊA, P. L. P. et al. Uma arquitetura de sistemas voltada para a integração de bases de dados distribuídas de biodiversidade. RBLAgro: Revista Brasileira de Agroinformática, v.6, n.1, p. 47-63, 2004.

DIEGUES, A. C. et al. Os saberes tradicionais e a biodiversidade no Brasil. São Paulo: NUPAUB/USP, PROBIO/MMA, CNPq, 2000. 211 p.

ELISABETSKY, E. Etnofarmacologia. Ciência e Cultura, São Paulo, v.55, n.3, p.35-36, 2003.

FONSECA, M. O. Informação e direitos humanos: acesso às informações arquivísticas. Ciência da Informação, Brasília, v.28, n.2, p. 146-154, 1999.

FRANZON, S. Direito à informação ambiental. Revista SPEI, Curitiba v.4, n.1, p. 31-38, 2003.

FUNK, V. A. et al. The importance of vouchers. Taxon, v.54, n.1, p. 127-129, 2005.

GAIKWAD, J.; CHAVAN, V. Open Access and biodiversity conservation: challenges and potentials for the developing world. Data Science Journal, v.5, p. 1-17, 2006.

GONÇALVES, J. S.; JUNQUEIRA, J. R. C. D. M. Propriedade intelectual como fonte de financiamento de P\&D: compatibilização de dispositivos da Constituição paulista com a irradiação da inovação tecnológica ao sistema produtivo dos agronegócios estaduais. Informações Econômicas, São Paulo, v.34, n.8, p. 53-80, 2004.

GONZALEZ, M. Quantificação de custo e tempo no processo de informatização das coleções biológicas brasileiras: a experiência do herbário do Instituto de Pesquisas Jardim Botânico do Rio de Janeiro. Rodriguesia, Rio de Janeiro, v.60, n.3, p. 11, 2009.

GRAHAM, C. H. et al. New developments in museum-based informatics and applications in biodiversity analysis. Trends in Ecology and Evolution, v.19, n.9, p. 497-503, 2004.

GRAMMONT, P. C.; CUARÓN, A. D. An evaluation of threatened species categorization systems used on the American continent. Conservation Biology, v.20, p. 14-27, 2006.

HOUSE, N. A. V. Digital libraries and practices of trust: networked biodiversity information. Social Epistemology, v.16, n.1, p. 99-114, 2002. 
Análise das restrições de acesso a dados de espécies ameaçadas, previstas em políticas de coleções biológicas científicas brasileiras...

INTER AMERICAN BIODIVERSITY INFORMATION NETWORK. Proposed methdology to measure indicators for the project "Building the Inter-american Biodiversity Information Network." IABIN, 2007. 14 p. Disponível em: http://www. iabin.net $/$ index.php?option $=$ com_docman\&task $=$ doc_ details\&gid $=24 \&$ Itemid $=24$

INSTITUTO NACIONAL DE PESQUISA DA AMAZÔNIA. Política de acesso a dados e informações: Programa de Coleções e Acervos Científicos do Instituto Nacional de Pesquisas da Amazônia/MCT. 5 p. 2006.

KEUNECKE, K. Das bases de dados: proteção jurídica no âmbito da Propriedade Intelectual. ABPI: Revista da Associação Brasileira da Propriedade Industrial, Rio de Janeiro, v. 57 , p. 48-55, 2002.

KURAMOTO, H. Informação científica: proposta de um novo modelo para o Brasil. Ciência da Informação, Brasília, v.35, n.2, p. 91-102, 2006.

LANE, M. A. et al. Biodiversity informatics: the challenge of rapid development, large databases, and complex data (keynote). In: INTERNATIONAL CONFERENCE ON VERY LARGE DATA BASES, 26., 2000, Cairo. Proceedings... Cairo: Morgan Kaufmann, 2000. p. 729-732.

LIMA, P. D. B. A excelência em gestão pública: a trajetória e a estratégia do Gespública. Rio de Janeiro: Qualitymark, 2007. 248 p.

LISBOA, M.; BARROS, J. N. Direito bumano ao meio ambiente. Curitiba: Dhesca Brasil/INESC, 2008. v.2, 44 p. (Coleção Cartilhas de Direitos Humanos).

MAGALHÃES, C. et al. Automação de coleções biológicas e informações sobre a biodiversidade da Amazônia. Parcerias Estratégicas, Brasília, v.12, p. 294-312, 2001.

MASCARENHAS, G. C. C. A biodiversidade brasileira no âmbito do Acordo TRIPS. Revista Brasileira de Inovação, Campinas, v.3, n.2, p. 393-416, 2004.

MINISTÉRIO DA CIÊNCIA E TECNOLOGIA. Diretrizes e estratégias para a modernização de coleções biológicas brasileiras e a consolidação de sistemas integrados de informação sobre biodiversidade. Brasília: CGEE/ PPBio/ MCT, 2006a. 324 p.

Minuta de política de dados: versão aprovada pelo Conselho Diretor: Programa de Pesquisa em Biodiversidade (PPBio)/Ministério de Ciência e Tecnologia (MCT). 8 p. 2006.

NASCIMENTO, M. A. L. D.; MAGALHÃES, L. M. S. Categorias de espécies ameaçadas de extinção e seu significado para a conservação da biodiversidade. Floresta e Ambiente, Seropédica, RJ, v.5, n.1, p. 146-159, 1998.

Ci. Inf., Brasília, DF, v. 39 n. 1, p.33-50, jan./abr., 2010
NOVAES, W. et al. Agenda 21 brasileira: bases para discussão. Brasília: MMA/PNUD, 2000.

OLIVEIRA, F. D. P. M. D. Pressupostos para uma teoria geral do direito processual ambiental. Revista Direito e Liberdade, Mossoró, v.1, n.1, p. 127-165, 2005.

ORTELLADO, Pablo. As políticas nacionais de acesso à informação científica. Liinc em Revista, Rio de janeiro, v.4, n.2, p. 186-195, 2008. Disponível em: http:/ / revista.ibict.br/liinc/ index.php/liinc/issue/view/34

PAIVA, A. F. D. Proteção jurídica dos bancos de dados. Revista de Derecho Informático, v.87, 2005.

PARANAGUÁ, P. Patentes. In: LEMOS, R. (Ed.). Propriedade intelectual: roteiro de curso. Rio de Janeiro: FGV, 2008.

PEIXOTO, A. L. Coleções biológicas de apoio ao inventário, uso sustentável e conservação da biodiversidade. Rio de Janeiro: Instituto de Pesquisas Jardim Botânico do Rio de Janeiro, 2003.

PEIXOTO, A. L; MORIN, M. P. Coleções botânicas: documentação da biodiversidade brasileira. Ciência e Cultura, São Paulo, v.55, n.3, p. 21-24, 2003.

PIMENTA, E. S. Código de direitos autorais e acordos internacionais. São Paulo: Lejus, 1998.

PIRES, Paulo de Tarso de Lara et al. O imposto territorial rural (ITR) e a sua influência sobre a atividade florestal: um estudo de caso. Floresta, Curitiba, v.31, n.1-2, p. 84-90, 2001.

REGAN, Helen M.; COLYVAN, Mark. Fuzzy sets and threatened species classification. Conservation Biology, v.14, n.4, p. 1197-1199, 1999.

RIVA, Ana Luisa M. da; FONSECA, Luis Fernando Laranja da; HASENCLEVER, Leonardo. Instrumentos econômicos e financeiros para a conservação ambiental no Brasil: uma análise do estado da arte no Brasil e no Mato Grosso: desafios e perspectivas. Brasília: Instituto Socioambiental, 2007.

SANTOS, André Antônio Souza; GÓES, Jamille Argôlo. Considerações sobre a preservação da biodiversidade e o papel da Lei no 11.284/06. Jus Navigandi, Teresina, ano 10, n. 1036, 03 maio 2006.

SANTOS, Antônio Silveira R. dos. Direito à informação na esfera ambiental. Boletim de Direito Administrativo, v.16, n.10, p. 729-730, 2000.

SANTOS, Luiz Alberto dos. Prestação de contas, acesso à informação e participação e processo decisório governamental. In: CONGRESO INTERNACIONAL DEL CLAD SOBRE LA REFORMA DEL ESTADO Y DE LA ADMINISTRACIÓN PÚBLICA, 10., 2005, Santiago. Anais... Santiago: CDLA, 2005. 20 p. 
SCARANO, Fabio Rubio. O jardim botânico do futuro. In: JARDIM BOTÂNICO DO RIO DE JANEIRO (Ed.). Jardim Botânico do Rio de Janeiro 1808-2008. Rio de Janeiro: Instituto de Pesquisas Jardim Botânico do Rio de Janeiro, 2008. p. 15-19.

SCHOLES, R. J. et al. Toward a global biodiversity observing system. Science, v. 321, p. 1044-1045, 2008.

SFREDDO, J. A.; FLORES, D. O controle de acesso na percepção dos profissionais de arquivo: uma questão de segurança das informações institucionais. Perspectivas em Ciência da Informação, Belo Horizonte, v.19, n.2, p. 121-140, 2009.

SILVA, M. Lei 11.371 e a proteção jurídica das bases de dados. Florianópolis: Associação de Empresas Brasileiras de Tecnologia da Informação, Software e Internet de Santa Catarina (ASSESPRO/SC), 2008.

SOUZA, G. M.; BUCKERIDGE, M. S. Sistemas complexos: novas formas de ver a botânica. Revista Brasileira de Botânica, São Paulo, v.27, n.3, p. 407-419, 2004.
TAVARES, C.; FREIRE, I. M. Informação ambiental no Brasil: para quê e para quem. Perspectivas em Ciência da Informação, Belo Horizonte, v.8, n.2, p. 208-215, 2003.

VILAS BOAS, S. (Org.). Formação e informação ambiental: jornalismo para iniciados e leigos. São Paulo: Summus, 2004. 204 p. (Coleção Formação \& informação).

VIVACQUA, M.; VIEIRA, P. F. Conflitos socioambientais em unidades de conservação. Politica \& Sociedade, Florianópolis, v.4, n.7, p. 139-162, 2005.

YOSHIDA, C. F. T. et al. Coleções biológicas: gestão, planejamento e propriedade industrial. SIMPÓSIO NACIONAL DE COLEÇÕES CIENTÍFICAS: EVENTO COMEMORATIVO AOS 105 ANOS DO INSTITUTO OSWALDO CRUZ, 1., 2005, Rio de Janeiro. Anais... Rio de Janeiro: Fiocruz, 2005. p. 33-36. 